\title{
Dynamic restructuring of coordinatively unsaturated copper paddle wheel clusters drives $\mathrm{CO}_{2}$ reduction efficiently
}

\section{Wei Zhang}

Central China Normal University

\section{Chuqiang Huang}

Central China Normal University https://orcid.org/0000-0002-7049-0936

Jiexin Zhu

Wuhan University of Technology https://orcid.org/0000-0003-1629-240X

Qiancheng Zhou

Central China Normal University

\section{Ruohan Yu}

Wuhan University of Technology

\section{Yali Wang}

Central China Normal University

\section{Pengfei An}

Institute of High Energy Physics Chinese Academy of Sciences

\section{Jing Zhang}

Institute of high energy physics, chinese academy of science

\section{Ming Qiu}

Central China Normal University

\section{Liang Zhou}

Wuhan University of Technology

\section{Liqiang Mai}

Wuhan University of Technology https://orcid.org/0000-0003-4259-7725

\section{Zhiguo Yi}

Chinese Academy of Sciences

\section{Ying Yu ( $\square$ yuying01@mail.ccnu.edu.cn )}

Central China Normal University https://orcid.org/0000-0002-7680-7180

\section{Article}

Keywords: electrocatalyst, coordinatively unsaturated sites, copper paddle wheel, $\mathrm{CO} 2$ reduction 
Posted Date: April 2nd, 2021

DOI: https://doi.org/10.21203/rs.3.rs-354259/v1

License: (c) (i) This work is licensed under a Creative Commons Attribution 4.0 International License. Read Full License 


\section{Abstract}

Coordinatively unsaturated metal sites in metal-organic frameworks (MOFs) hold promises for improving activity and selectivity of catalyst. As the building unit of many MOFs, copper paddle-wheel (CPW) is of great interest to function as activity sites for $\mathrm{CO}_{2}$ reduction due to the ability of copper cations to attract and activate $\mathrm{CO}_{2}$ molecules. However, little is known about the real structure of these active sites for their dynamic structural changes under realistic operating conditions. Here, we apply to design defect metal-organic framework HKUST-1 with coordinatively unsaturated copper paddle wheel through a facile "atomized trimesic acid" strategy, reveal its dynamic behaviour during electrochemical reconstruction and prove its superior $\mathrm{CO}_{2}$ reduction activity. Through comprehensive analysis of various in situ spectroscopy characterizations, it is demonstrated that unsaturated copper paddle wheel clusters [CU-CPWC, $\mathrm{Cu}_{2}(\mathrm{HCOO})_{3}$ ] are finally formed during electrochemical reconstruction and act as the real active sites. Mechanistic studies based on density functional theory calculations reveal that the higher $d$ band center in CU-CPWC compared with that in CPW accelerates the electron transport from copper atoms to $\mathrm{CO}_{2}$ molecules, which can be exploited to improve the $\mathrm{CO}_{2}$ reduction performance.

\section{Background}

Coordinatively unsaturated metal sites in metal-organic frameworks (MOFs) hold promises for improving activity and selectivity of catalyst. As the building unit of many MOFs, copper paddle-wheel (CPW) is of great interest to function as activity sites for $\mathrm{CO}_{2}$ reduction due to the ability of copper cations to attract and activate $\mathrm{CO}_{2}$ molecules. However, little is known about the real structure of these active sites for their dynamic structural changes under realistic operating conditions. Here, we apply to design defect metal-organic framework HKUST-1 with coordinatively unsaturated copper paddle wheel through a facile "atomized trimesic acid" strategy, reveal its dynamic behaviour during electrochemical reconstruction and prove its superior $\mathrm{CO}_{2}$ reduction activity. Through comprehensive analysis of various in situ spectroscopy characterizations, it is demonstrated that unsaturated copper paddle wheel clusters [CU-CPWC, $\mathrm{Cu}_{2}(\mathrm{HCOO})_{3}$ ] are finally formed during electrochemical reconstruction and act as the real active sites. Mechanistic studies based on density functional theory calculations reveal that the higher $d$ band center in CU-CPWC compared with that in CPW accelerates the electron transport from copper atoms to $\mathrm{CO}_{2}$ molecules, which can be exploited to improve the $\mathrm{CO}_{2}$ reduction performance.

Due to the constituents' geometry, size, and functionality can be flexibly varied, metal-organic frameworks (MOFs) materials represent ideal platforms that can control the interplay between efficiency, activity and selectivity in a single catalytic system. ${ }^{1-4}$ HKUST-1 is the prime example of MOFs based on copper paddle wheel $\left(-\mathrm{Cu}_{2}(\mathrm{COO})_{4}\right.$, metal node) and 1,3,5-benzene-tricarboxylic acid $\left(\mathrm{H}_{3} \mathrm{BTC}\right.$, organic link), which has the potential to be used in whole catalysis world ${ }^{5}$ Interest in the reactivity of metal copper and copper based MOFs stems from its unique electrochemistry $\mathrm{CO}_{2}$ reduction selectivity toward higher-value hydrocarbons beyond $\mathrm{CO}^{6-15}$ Defect engineering in MOFs, such as missing linker defects, has attracted considerable research attention since it offers a means to construct coordinatively unsaturated metal 
sites, which is generally considered to be the active sites, and thus has important implications for improving the catalytic performance. ${ }^{16-23}$ Therefore, constructing coordinatively unsaturated copper paddle wheel in HKSUT-1 may be served to facilitate the catalytic activity. So far, there has been rare report about it.

A critical question remaining to be addressed here is that little is known about the real structure of these active sites. Exploring the dynamic restructuring of electrocatalysts has been of interest for a long time, which is crucial to understand structure-reactivity correlations in many catalysis systems. ${ }^{24-29}$ But it has proved challenging to relate local electronic and geometric structure of these open metal sites to catalytic function. The difficulty arises from the dynamic change of electrocatalyst structure in local coordination under electrochemical reactive environments. ${ }^{10,30}$ The changes in structure and surface composition control catalytic function. Especial challenge is identifying the real active sites of MOFs-based catalysts owing to the complexity of their structure, but it may lead to shift the catalyst design from trial-and-error paradigm to a rational approach.

Herein, we report a defect-engineered metal-organic framework HKUST-1 with coordinatively unsaturated copper paddle wheel, which is named "quasi-MOF (QMOF)", as pre-catalyst for electrocatalytic $\mathrm{CO}_{2}$ reduction and reveal its dynamic behaviour during electrochemical reconstruction. Several unique aspects of this work are worth highlighting up in front: (1) defect metal-organic framework HKUST-1 with coordinatively unsaturated copper paddle wheel was synthesized through a facile "atomized trimesic acid" strategy; (2) unsaturated copper paddle wheel clusters [CU-CPWC, $\mathrm{Cu}_{2}(\mathrm{HCOO})_{3}$ ] were identified as real catalytic active site thanks to experimental results using a series of quasi-in situ and in situ characterization methods; (3) a boost in reaction activity for $\mathrm{CO}_{2}$ reduction was observed owing to the structure with the superior $\mathrm{CO}_{2}$ activation ability.

\section{Results}

Synthesis and structural characterization of QMOF. Previous investigation has indicated that the crystallization of the MOFs undergoes Ostwald ripening process, during which unsaturated metal sites (UMS) may be observed. ${ }^{31}$ With this in mind, retarding the crystal ripening process can generate more UMS in MOFs, so as to obtain more open metal sites for electrocatalytic reaction. The synthetic procedures of catalysts are illustrated in Figure $\mathbf{1} \mathbf{a}$ and $\mathbf{b}$, and the experimental details are summarized in Supplementary Information. $\mathrm{Cu}(\mathrm{OH})_{2}$ nanowires (NWs) with smooth surface were first grown on Cu foil based on a reported chemical oxidation method. ${ }^{32}$ Subsequently, $\mathrm{Cu}(\mathrm{OH})_{2}$ sample was reacted with atomized 1,3,5-benzenetricarboxylic acid (trimesic acid, $\mathrm{H}_{3} \mathrm{BTC}$ ) solution for $60 \mathrm{~s}$ to form uniform quasiMOF (QMOF) clusters on $\mathrm{Cu}(\mathrm{OH})_{2}$ NWs surface, as illustrated in Figure 1a. The electrochemical reconstruction was undertaken by electrochemically reducing QMOF in $0.1 \mathrm{M} \mathrm{KHCO}_{3}$ electrolyte at $-0.4 \mathrm{~V}$ vs reversible hydrogen electrode (RHE) to form $\mathrm{CU}-\mathrm{CPWC}$ catalyst. For comparison, $\mathrm{Cu}(\mathrm{OH})_{2}$ sample was reacted with sufficient $\mathrm{H}_{3}$ BTC solution to form complete MOF crystal (CMOF), as illustrated in Figure 1b. 
Scanning electron microscopy (SEM) and transmission electron microscopy (TEM) images confirmed the synthesis of a smooth-surface nanowire structure (Supplementary Figure S1 and S2). X-ray diffraction (XRD) patterns verified the presence of a crystalline $\mathrm{Cu}(\mathrm{OH})_{2}$ phase (Figure 1c), which was further evidenced by Raman spectroscopy (Figure 1d). Note that no diffraction peaks for HKUST-1 were detected in QMOF (Figure 1c), suggesting an amorphous structure may be formed.

In order to investigate the surface structure of samples, we performed Raman and Fourier transform infrared (FT-IR) analysis. The high-frequency region ranging from $700 \sim 1200 \mathrm{~cm}^{-1}$ is dominated by bands associated with the organic part of HKUST-1 (Figure 1d). ${ }^{33-35}$ The band at $1006 \mathrm{~cm}^{-1}$ corresponds to $\mathrm{C}=\mathrm{C}$ symmetric stretching of benzene ring. At 827 and $748 \mathrm{~cm}^{-1}$, the out-of-plane ring $(\mathrm{C}-\mathrm{H})$ bending vibrations are recognized in QMOF and CMOF. ${ }^{33,35}$ QMOF exhibits weaker bands in high-frequency region than CMOF, suggesting UMS of QMOF. In the low-frequency region, the doublet at 458 and $505 \mathrm{~cm}^{-1}$ is related to $\mathrm{Cu}-\mathrm{O}$ stretching modes involving oxygen atoms of carboxylate bridges, which is consistent with previous reports, suggesting the metal-organic coordination in the samples. ${ }^{7,35}$ Vibrational properties of the samples were further investigated by FT-IR spectroscopy. As shown in Figure 1e, the QMOF and CMOF exhibit the significant peaks ranging from 1100 to $1800 \mathrm{~cm}^{-1}$ compared with $\mathrm{Cu}(\mathrm{OH})_{2} \mathrm{NWs}$.

Characteristic peaks assigned to vibrations of the carboxylate group in HKUST-1 are observed: 1370 and $1419 \mathrm{~cm}^{-1}$ corresponding to the symmetric vibrations of -COO groups and 1450, 1592 and $1646 \mathrm{~cm}^{-1}$ attributed to the asymmetric vibrations of -COO groups. ${ }^{8,34,36}$ The peak at $1114 \mathrm{~cm}^{-1}$ is assigned to C-O vibration in the HKUST-1. In addition, the peaks at 732 and $762 \mathrm{~cm}^{-1}$ are observed in CMOF, which can be ascribed to the bonding of Cu with BTC linker molecules (Figure 1e). ${ }^{7}$ A weak peak at $1545 \mathrm{~cm}^{-1}$ is also found in CMOF, which is due to water coordinated with $\mathrm{Cu}$ in the MOF. ${ }^{34}$ Meanwhile, for the QMOF, two features of the FT-IR spectrum are worth noting. Firstly, notable shifts to lower wavenumber are observed for the peaks of asymmetric vibrations of -COO groups, suggesting an elongation of the associated bonds. Secondly, the peaks at $1545 \mathrm{~cm}^{-1}$ (water coordinated with $\mathrm{Cu}$ in the MOF), $1419 \mathrm{~cm}^{-1}$ (one of the symmetric vibrations of -COO groups) and $732 \mathrm{~cm}^{-1}$ (one of the Cu with BTC linker molecules) in QMOF are undetectable, which indicates that a defective HKUST-1 structure with UMS or distorted metal nodes may be formed in QMOF.

Notably, SEM and TEM images of QMOF reveal that the uniform nanowire structure with many small clusters on the surface (Figure 2a-e). As shown in Figure $\mathbf{2 d}$ and e, small clusters are clearly observed in the high-resolution TEM (HR-TEM) images. Figure $\mathbf{2 f - j}$ show the scanning TEM (STEM) and corresponding energy dispersive X-ray spectroscopy (EDS) elemental mapping images of QMOF, confirming the existence and uniform distribution of elemental $\mathrm{Cu}, \mathrm{O}$ and $\mathrm{C}$ in the nanowires.

Moreover, the structural evolution of the $\mathrm{Cu}(\mathrm{OH})_{2} \mathrm{NWs}$ in the presence of the atomized $\mathrm{H}_{3} \mathrm{BTC}$ was explored. As shown in Supplementary Figure S3, the controllable structural evolution from QMOF clusters to complete MOF crystal (CMOF) is achieved through controlling the reaction time with "atomized $\mathrm{H}_{3} B T C$ ". In order to prove the superiority of "atomized $\mathrm{H}_{3} \mathrm{BTC}$ " method, common "immersed method" was 
performed, that is, $\mathrm{Cu}(\mathrm{OH})_{2} \mathrm{NWs}$ precursor was submersed into liquid $\mathrm{H}_{3} \mathrm{BTC}$ solution to synthesize HKUST-1. As a contrast, only CMOF is obtained by the ordinary "immersed method" even in a short time of $10 \mathrm{~s}$ (Supplementary Figure S3d). SEM image of CMOF reveals a typical octahedral HKUST-1 morphology (Supplementary Figure S3c), which is consistent with previous reports. ${ }^{37-39}$ High

magnification SEM and TEM images identify $\mathrm{Cu}(\mathrm{OH})_{2} \mathrm{NWs}$ trace in CMOF (Supplementary Figure S4), further revealing the structural evolution from $\mathrm{Cu}(\mathrm{OH})_{2} \mathrm{NWs}$ to CMOF.

The surface hydrophilicity and $\mathrm{CO}_{2}$ capture capability of the samples were characterized by contact angle and $\mathrm{CO}_{2}$-temperature programmed desorption (TPD) measurements (Supplementary Figure S5 and S6). Contact angle measurements illustrated that $\mathrm{Cu}(\mathrm{OH})_{2}$ surface is the most hydrophilic. The surface clusters of QMOF decrease the hydrophilicity of $\mathrm{Cu}(\mathrm{OH})_{2}$, but increase the $\mathrm{CO}_{2}$ capture capability.

Electrochemical reconstruction of QMOF and CMOF. Attention was then paid to the structural changes of QMOF and CMOF during the electrochemical reconstruction process. X-ray photoelectron spectroscopy (XPS) tests under ex-situ (Figure 3a-c) and quasi-in situ (Figure 3d-e) conditions were first performed to reveal the electronic configuration of each catalyst before and after electrochemical reconstruction.

The ex-situ XPS spectra of C 1s for QMOF and CMOF are shown in Figure 3a, which can be divided into four peaks, including sp ${ }^{2}$ carbon in benzene ring $(284 \mathrm{eV}), \mathrm{sp}^{3}$ carbon $(\mathrm{C}-\mathrm{C}, 284.8 \mathrm{eV}), \mathrm{C}-\mathrm{O}(286 \mathrm{eV})$ and $\mathrm{C}=\mathrm{O}(289 \mathrm{eV}) \cdot{ }^{40-43}$ The metal node $\left[-\mathrm{Cu}_{2}(\mathrm{COO})_{4}\right]$ defect of QMOF is further confirmed by the lower binding energy shift of $\mathrm{C}-\mathrm{O}$ peak compared with that of CMOF. Note that an additional $\mathrm{O} 1 \mathrm{~s}$ peak at $533.2 \mathrm{eV}$ is clearly observed in QMOF, which is related to $\mathrm{H}_{2} \mathrm{O}$ molecule (Figure $3 \mathbf{b}$ ). ${ }^{44,45}$ This result has been confirmed by FT-IR peak at $1545 \mathrm{~cm}^{-1}$, corresponding to water coordinated with $\mathrm{Cu}$ in the MOF, as described above. $01 \mathrm{~s}$ spectra of QMOF and CMOF both display two peak regions at approximately 530.5 and $531.8 \mathrm{eV}$, which can be assigned to the $\mathrm{Cu}-\mathrm{O}$ and $-\mathrm{COO}$ groups. ${ }^{43}$ As expected, the QMOF sample exhibits the lower binding energy of $\mathrm{Cu}-\mathrm{O}$ and $-\mathrm{COO}$ than $\mathrm{CMOF}$ for the defect of metal nodes [$\mathrm{Cu}_{2}(\mathrm{COO})_{4}$ ] in QMOF. XPS data for the $\mathrm{Cu} 2 \mathrm{p}_{3 / 2}$ exhibit $\mathrm{Cu}^{2+}$ and $\mathrm{Cu}^{1+}$ characteristic peak (Supplementary Figure S7). ${ }^{41,46}$ Previous report suggests the conversion of $\mathrm{Cu}^{2+}$ to $\mathrm{Cu}^{1+}$ in $\mathrm{CMOF}$ is induced by the exposure of MOF to X-ray source and charge neutralizer during XPS data collection. ${ }^{46}$ Note that Cu Auger $\left(L_{3} M_{45} M_{45}\right)$ region shows that a reduced oxidation state for the Cu species in QMOF, which may be attributed to the lower coordinatively unsaturated $\mathrm{Cu}$ atoms (Figure $3 \mathrm{c}$ ). ${ }^{47}$

Furthermore, the electronic structures and chemical bonding of $\mathrm{Cu}$ atoms in their local environment were investigated by X-ray absorption spectroscopy (XAS), including X-ray absorption near-edge structure (XANES) and extended X-ray absorption fine structure (EXAFS) spectroscopy. The QMOF sample exhibits lower-energy edge position as compared with $\mathrm{CMOF}$, indicating a reduced oxidation state for the $\mathrm{Cu}$ species (Supplementary Figure S8), which is consistent with XPS auger spectrometry (Figure 3c). The dominant coordination peaks in EXAFS can be ascribed to Cu-O (EXAFS, Supplementary Figure S9). 
Overall, a comprehensive study of ex-situ XPS, XAS, FT-IR, and Raman provides clear evidence that quasi MOF with UMS has been formed in QMOF sample.

Significant changes were observed in the XPS spectra for CU-CPWC and CPW under quasi-in situ condition, of which the detail is shown in Experimental Section. $C 1 s$ spectra in Figure $3 \mathbf{d}$ shows that $s p^{2}$ carbon in benzene ring $(284 \mathrm{eV})$ is not detected in the samples, indicating the loss of organic coordinating ligands (linkers) during electrochemical reconstruction. But the peaks corresponding to $\mathrm{C}-\mathrm{O}$ and $\mathrm{C}=\mathrm{O}$ in the metal nodes $\left[-\mathrm{Cu}_{2}(\mathrm{COO})_{4}\right]$ still show up (Figure $3 \mathrm{~d}$ ). Figure $3 e$ displays that the $-\mathrm{COO}$ groups peaks ( 532.0 and $532.2 \mathrm{eV}$ ) in CU-CPWC and CPW have shifted towards higher binding energy compared with those in QMOF and CMOF, suggesting that the lost organic coordinating ligands may be replaced by hydrogen during electrochemical reconstruction. The peaks at $536.2 \sim 537.0 \mathrm{eV}$ assigned to $\mathrm{CO}_{2}$ molecule are also observed (Figure $3 \mathrm{e}$ ), due to the superior $\mathrm{CO}_{2}$ adsorption capacity. ${ }^{44}$ The presence of $\mathrm{Cu}^{0}$ and $\mathrm{Cu}^{1+}$ characteristic peak indicates a reduced oxidation state for the $\mathrm{Cu}$ species (Figure $3 \mathrm{f}$ ). Based on these findings, it is suggested that $\left[\mathrm{Cu}_{2}(\mathrm{HCOO})_{4}\right]$ cage and defective low-coordinated $\left[\mathrm{Cu}_{2}(\mathrm{HCOO})_{4-\mathrm{x}}\right](0<\mathrm{x}<4)$ cage may be formed in CMOF and QMOF respectively after electrochemical reconstruction.

In order to further gain insight into the dynamic electronic structures and chemical state of the $\mathrm{Cu}$ active site during $\mathrm{CO}_{2} \mathrm{RR}$, in situ XAS were investigated under real operating conditions at $-0.4 \mathrm{~V}$ vs RHE in aqueous $\mathrm{CO}_{2}$-saturated $0.1 \mathrm{M} \mathrm{KHCO}_{3}$. Figure 4a presents the schematic of XAFS set-up and recording processes for the in situ spectro-electrochemistry experiment. Figure $4 \mathrm{~b}$ shows the $\mathrm{Cu}$ K-edge XANES spectra with electron transitions from $1 s$ to $4 p$ states, including $1 s \rightarrow 4 p_{\mathrm{z}}$ transition $(\mathrm{A})$, and the $1 s \rightarrow$ $4 p_{x, y}$ transition $(B, C){ }^{25,48-51}$ The higher absorption edge position and the lower $1 \mathrm{~s} \rightarrow 4 p_{z}$ transition intensity indicate a gradually oxidized Cu species. ${ }^{50-52}$ Furthermore, FT-EXAFS spectra in Figure $4 \mathrm{c}$ reveal detailed

information regarding the local coordination environment of $\mathrm{Cu}$. The dominant peak at approximately 2.2 $\AA$, which is assigned to the coordination of $\mathrm{Cu}-\mathrm{Cu}$, is clearly observed in $\mathrm{Cu}$ foil, $\mathrm{ER}-\mathrm{Cu}(\mathrm{OH})_{2}$ and $\mathrm{CU}$ $\mathrm{CPWC}$. Note that the existence of $\mathrm{Cu}-\mathrm{O}$ coordination peak suggests the oxygen-bearing copper clusters may be formed in CU-CPWC. Meanwhile, the Cu-O coordination (approximately $1.5 \AA$ ) is the main peak in CPW (Figure 4c). A straight comparison of XAS data before and after electrochemical reconstruction is shown in Supplementary Figure S10, highlighting the changes of coordination environment in the samples.

An additional analysis of Morlet wavelet-transform (WT) was performed to better understand the local structure of $\mathrm{Cu}$ atoms. As shown in Figure $4 \mathrm{~d}, \mathrm{ER}-\mathrm{Cu}(\mathrm{OH})_{2}$ exhibits an intensity maximum at approximately $7.2 \AA^{-1}$, which is very close to that in the reference Cu foil. Note that a slightly higher WT maximum at about 8.1 $\AA^{-1}$ is observed in QMOF, indicating the influence of oxygen on the local coordination environment of copper. Furthermore, two intensity maximums at 5.2 and $9.8 \AA^{-1}$, corresponding to $\mathrm{Cu}-\mathrm{O}$ and $\mathrm{Cu}-\mathrm{Cu}$ shells, is visible in $\mathrm{CU}-\mathrm{CPWC}$. 
To better understand the stepwise structure evolution process of HKUST-1, more in-depth localized observations were performed by in situ Raman and in situ FT-IR. Figure 4e shows in situ Raman spectra measured at $-0.4 \mathrm{~V}$ vs $\mathrm{RHE}$ in aqueous $\mathrm{CO}_{2}$-saturated $0.1 \mathrm{M} \mathrm{KHCO}_{3}$ and a time resolution of about $30 \mathrm{~s}$. The nethermost spectrum is the first collected data. In situ Raman results show that the peak attributed to $\mathrm{C}-\mathrm{H}$ and $\mathrm{C}=\mathrm{C}$ peaks disappeared, indicating the loss of organic ligands during electrochemical reconstruction. In pursuit of a molecular-level understanding of electrochemical reconstruction for catalyst, advanced in situ ATR FT-IR was employed to dynamically monitor the structure evolution at the fixed potential of -0.4 V (Supplementary Figure S11 and S12). As shown in Supplementary Figure S12, the peak at $1370 \mathrm{~cm}^{-1}$ corresponding to the symmetric vibrations of - $\mathrm{COO}$ groups in $\left[\mathrm{Cu}_{2}(\mathrm{HCOO})_{4-x}\right]$ cage becomes stronger as the reaction progresses. This further confirms the loss of organic ligands and $\left[\mathrm{Cu}_{2}(\mathrm{HCOO})_{4-\mathrm{x}}\right]$ cage is exposed during electrochemical reconstruction.

Based on the above results, we can reasonably speculate about the structure of the $\left[\mathrm{Cu}_{2}(\mathrm{HCOO})_{4-x}\right]$ cage in CU-CPWC and perform quantitative EXAFS curve-fitting analysis to reveal the quantitative coordination configuration of $\mathrm{Cu}$ atoms. A previous investigation has shown that $\mathrm{Cu}$ easily forms paddle-wheel dinuclear $\mathrm{Cu}$ (ii) carboxylate coordination compounds. ${ }^{53} \mathrm{~A}$ good fitting of the experimental FT-EXAFS data is achieved by the simulated EXAFS based on tricoordinated $\left[\mathrm{Cu}_{2}(\mathrm{HCOO})_{3}\right]$ cage model for CU-CPWC (Supplementary Figure S13c). The typical tetracoordinate copper paddle wheel $\left[\mathrm{Cu}_{2}(\mathrm{HCOO})_{4}\right]$ cage model fits well with experimental FT-EXAFS data of CPW (Supplementary Figure S13d).

In order to clarify the details of the adsorption and activation of $\mathrm{CO}_{2}$ on CU-CPWC, in situ XAS data were recorded in aqueous $\mathrm{CO}_{2}$ and $\mathrm{Ar}$-saturated $0.1 \mathrm{M} \mathrm{KHCO}_{3}$, respectively. It can be found that the Cu K-edge of CU-CPWC shows the lower $1 \mathrm{~s} \rightarrow 4 \mathrm{p}_{\mathrm{z}}$ transition intensity in $\mathrm{CO}_{2}$-saturated $\mathrm{KHCO}_{3}$ solution under $-0.4 \mathrm{~V}$ compared with that in Ar-saturated $\mathrm{KHCO}_{3}$ solution (Figure. 4f), which suggests an increase in the $\mathrm{Cu}$ oxidation state as a result of the charge transfer from $\mathrm{Cu}$ to the carbon $2 \mathrm{p}$ orbital in $\mathrm{CO}_{2}$ to form a $\mathrm{CO}_{2}{ }^{\delta-}$ species. ${ }^{54,55}$ The $\mathrm{Cu}$-Cu coordination peak slightly decreases in $\mathrm{CO}_{2}$-saturated $\mathrm{KHCO}_{3}$ solution (Figure. $\mathbf{4 g}$ ), which further confirms the increase in the Cu oxidation state compared with that in Ar-saturated $\mathrm{KHCO}_{3}$ solution.

The SEM image of CPW shows that the octahedral morphology has collapsed into irregular nanoparticles after electrochemical reconstruction (Supplementary Figure S14). These changes indicate the organic links are removed from HKUST-1 frames during reconstruction, resulting in large cleavages and structural collapse. The morphological change is also shown for CU-CPWC, as revealed in Supplementary Figure S15.

On the basis of these results from quasi-in situ XPS, in situ XAS, in situ Raman and in situ FTIR, it is concluded that the CU-CPWC sample surface has been modified by oxygen-bearing copper clusters based on coordinatively unsaturated $\left[\mathrm{Cu}_{2}\left(\mathrm{HCOO}_{4-x}\right]\right.$ cage. In order to verify whether the defect oxygen-bearing copper clusters promotes electrochemical $\mathrm{CO}_{2}$ reduction, we carried out $\mathrm{CO}_{2} \mathrm{RR}$ assessments on target catalyst CU-CPWC and the control samples including $\mathrm{Cu}$ foil, $\mathrm{ER}-\mathrm{Cu}(\mathrm{OH})_{2}$ and $\mathrm{CPW}$. 
Electrochemical activity of catalysts in $\mathrm{CO}_{2}$ reduction. We evaluated the electrochemical $\mathrm{CO}_{2}$ reduction activity using a gas-tight $\mathrm{H}$-cell system filled with $0.1 \mathrm{M} \mathrm{KHCO}_{3}$ solution. Prior to $\mathrm{CO}_{2} \mathrm{RR}$ testing at a given potential, all of the samples were subjected to a potential of $-0.4 \mathrm{~V}$ vs $\mathrm{RHE}$ in $\mathrm{CO}_{2}$-saturated $\mathrm{KHCO}_{3}$ solution for activation. As indicated by the linear sweep voltammetry (LSV) curves shown in Figure 5a, CU-CPWC shows the lower overpotentials at fixed current densities, suggesting the improved activity. The $\mathrm{CO}_{2}$ reduction product distribution of the four catalysts was investigated under various potentials (Supplementary Figure S16). As shown in Figure $\mathbf{5 b}$ and c, the CU-CPWC exhibits dramatically increased $\mathrm{CH}_{4}$ and $\mathrm{C}_{2} \mathrm{H}_{4}$ Faradaic efficiency among the four catalysts, benefiting from the superior $\mathrm{CO}_{2}$ capture and activation capability. Significantly, the total Faraday efficiency of $\mathrm{CO}_{2}$ reduction to $\mathrm{CH}_{4}$ and $\mathrm{C}_{2} \mathrm{H}_{4}$ has reached approximately $80.5 \%$ at $-0.90 \mathrm{~V}$.

Electrochemical impedance spectroscopy (EIS) tests were performed to investigate the kinetics of electrochemical processes. CU-CPWC exhibits the smaller Nyquist semicircle diameter than the control samples (Supplementary Figure S17), suggesting the fast charge-transfer kinetics in CRR. Cyclic voltammetry $(\mathrm{CV})$ measurements were then performed to determine the double-layer capacitances $\left(\mathrm{C}_{\mathrm{dl}}\right)$ (Supplementary Figure S18 and S19), which is related to electrochemical active surface area (ECSA). Not surprisingly, CU-CPWC exhibits the higher $\mathrm{C}_{\mathrm{dl}}$ than the control samples, indicating the larger ECSA, which is also an important contributor to the enhanced activity. In addition, LSV tests of the four samples in Arsaturated and $\mathrm{CO}_{2}$-saturated $\mathrm{KHCO}_{3}$ electrolyte were performed as well (Supplementary Figure $\mathrm{S} 20$ ). The higher current density in $\mathrm{CO}_{2}$-saturated $\mathrm{KHCO}_{3}$ electrolyte demonstrated that the carbon source for the evolved hydrocarbons comes from $\mathrm{CO}_{2}$, which provides a direct evidence for the reduction of $\mathrm{CO}_{2}$.

For clarifying the origin $\mathrm{CO}_{2} \mathrm{RR}$ mechanisms of $\mathrm{CU}-\mathrm{CPWC}$ and $\mathrm{CPW}$, the-first principles-based density functional theory (DFT) calculations were performed. The CU-CPWC and CPW models have been built and optimized, the detail of which is shown in Supporting Information. The spin-orbit projected 3d density of states of CU-CPWC and CPW are shown in Figure 5d. From this figure, the CU-CPWC presents obvious spin properties with asymmetrical spin distribution around the Fermi level. The $d$ band center of CU-CPWC and CPW is -1.16 and $-1.96 \mathrm{eV}$ respectively from the calculations, which indicates that the level change of $\mathrm{d}$ band center can be the intrinsic origins of the different $\mathrm{CO}_{2} \mathrm{RR}$ performance. ${ }^{56} \mathrm{In}$ addition, there are more states around the Fermi level for $\mathrm{Cu}-\mathrm{CPWC}$ model with $\mathrm{CO}_{2}$ adsorption (Figure 5e) than those of CUCPW model as shown in Figure 5f. It means that the CU-CPWC model has better electron transport behavior than that of CPW model, which can help to accelerate the reaction process. The data shown in Supplementary Figure S21, further support the statement.

CU-CPWC catalyst also exhibits good stability for $\mathrm{CH}_{4}$ and $\mathrm{C}_{2} \mathrm{H}_{4}$ generation under continuous $\mathrm{CO}_{2}$ electroreduction, as shown in Supplementary Figure S22. The Cu K-edge XANES spectra before and after stability testing reveal that the valence state shows negligible change after the constant-potential electrolysis (Supplementary Figure S23a), which is further confirmed by the first-derivative spectra of XANES (Supplementary Figure S23b). In addition, FT-EXAFS spectra show that the distinct Cu-O peak is 
still present after stability testing, indicating the structure stability of the CU-CPWC (Supplementary Figure S24).

\section{Conclusions}

Our results demonstrate that defect metal-organic framework HKUST-1 with coordinatively unsaturated copper paddle wheel, that is quasi-MOF clusters (QMOF), can be constructed through a facile "atomized trimesic acid" strategy. The restructuring mechanism based on hydrion substituting organic ligand during electrochemical reduction is revealed through a series of ex-situ, quasi-in situ and in situ characterization analysis, which indicates that unsaturated copper paddle wheel clusters $\mathrm{Cu}_{2}(\mathrm{HCOO})_{3}$ plays a key role in the catalytic function by facilitating $\mathrm{CO}_{2}$ activation on the CU-CPWC. It is expected that such facile "atomized" strategy and the coordinatively unsaturated copper paddle wheel clusters reported here are not unique to HKUST-1, but have general implications for other MOFs based catalyst systems.

\section{Methods}

Chemicals and materials. Trimesic acid $\left(\mathrm{H}_{3} \mathrm{BTC}\right)$, acetone, ethanol $\left(\mathrm{C}_{2} \mathrm{H}_{5} \mathrm{OH},\right)$, sodium hydroxide $(\mathrm{NaOH}$, AR), ammonium persulfate $\left(\left(\mathrm{NH}_{4}\right)_{2} \mathrm{~S}_{2} \mathrm{O}_{8}, 98 \%\right)$, hydrochloric acid $(\mathrm{HCl}, \mathrm{AR})$, potassium bicarbonate $\left(\mathrm{KHCO}_{3}, 99.7 \%\right)$, Copper foil $\left(99.99 \%, 0.2 \mathrm{~mm}\right.$ thick), carbon dioxide $\left(\mathrm{CO}_{2}, 99.99 \%\right)$, argon (Ar, 99.999\%), and helium (He, 99.99\%) were used as received. All chemicals were used directly without further purification. Deionized water was used for the preparation of all aqueous solutions.

Synthesis of $\mathrm{Cu}(\mathrm{OH})_{2}$ nanowires. In a typical synthesis, a uniform layer of blue $\mathrm{Cu}(\mathrm{OH})_{2}$ nanowires was firstly prepared by chemical oxidation of $\mathrm{Cu}$ foil. Each $\mathrm{Cu}$ foil piece was initially washed with hydrochloric acid (36\%) for 2 min to remove its native oxide layer, followed immediately by an ultrasonic cleaning in acetone, ethanol, and deionized water for 5 min sequentially. The cleaned Cu foil was immersed into 100 $\mathrm{mL}$ of an aqueous solution containing $5.2 \mathrm{~g} \mathrm{NaOH}$ and $2.282 \mathrm{~g}\left(\mathrm{NH}_{4}\right)_{2} \mathrm{~S}_{2} \mathrm{O}_{8}$ for $35 \mathrm{~min}$ at around $3{ }^{\circ} \mathrm{C}$. Then, the $\mathrm{Cu}$ foil was taken out of the solution, thoroughly rinsed with ultra-pure water, and dried with nitrogen. Thus, blue $\mathrm{Cu}(\mathrm{OH})_{2}$ nanowires were obtained.

\section{Synthesis of quasi-metal-organic frameworks HKUST-1 (QMOF) and complete-metal-organic frameworks HKUST-1 (CMOF) through "atomized method". The ligand solution $\left(\mathrm{H}_{3} \mathrm{BTC}\right)$ was prepared by mixing $10 \mathrm{~mL}$ of water, $20 \mathrm{~mL}$ of ethanol mixture, $0.20 \mathrm{~g}$ of $\mathrm{H}_{3} \mathrm{BTC}$ at room temperature. Subsequently, 15 $\mathrm{ml} \mathrm{H}_{3}$ BTC solution was atomized through a mini atomizer at room temperature (Philips, BSC601/05). Meanwhile, the $\mathrm{Cu}$ foil with a layer of $\mathrm{Cu}(\mathrm{OH})_{2}$ nanowires was reacted with atomized $\mathrm{H}_{3} \mathrm{BTC}$ solution for $60 \mathrm{~s}$, obtaining QMOF. To investigate the evolution of the MOFs growth, $\mathrm{Cu}(\mathrm{OH})_{2}$ nanowires was reacted with atomized $\mathrm{H}_{3} \mathrm{BTC}$ solution for 120,240 and $480 \mathrm{~s}$. When the reaction time was $480 \mathrm{~s}$, CMOF sample was obtained.}


Synthesis of complete-metal-organic frameworks HKUST-1 (CMOF) through "immersed method". For comparison, the $\mathrm{Cu}$ foil with a layer of $\mathrm{Cu}(\mathrm{OH})_{2}$ nanowires was immersed into the mixed $\mathrm{H}_{3} \mathrm{BTC}$ solution for different time for the final formation of CMOF.

\section{Material characterizations.}

(1) Fourier Transform Infrared Spectroscopy (FT-IR) and in situ Raman. FT-IR was carried out on Thermo Scientific Nicolet iN10 FTIR Microscope (Thermo Nicolet Corporation, Madison, WI, USA). In situ Raman scattering spectra were recorded on a LabRAM HR JY-Evolution microscope using a $532 \mathrm{~nm}$ argon ion laser. A customized in situ cell was employed for collecting in situ Raman data under atmosphere pressure in $\mathrm{CO}_{2}$-saturated $0.1 \mathrm{M} \mathrm{KHCO} 3$ aqueous electrolyte. The laser power was set to $50 \%$ and the acquisition time was $30 \mathrm{~s}$.

(2) Temperature programmed reduction (TPR)- $\mathrm{CO}_{2}$. The TPR- $\mathrm{CO}_{2}$ experiment was carried out on a BELCAT II (Microtrac BEL). The sample $(0.5 \mathrm{~g})$ was loaded into a quartz tube and swept with argon at 100 ${ }^{\circ} \mathrm{C}$ for $120 \mathrm{~min}$. After being cooled down to $40{ }^{\circ} \mathrm{C}$, the sample was loaded with $\mathrm{CO}_{2}$ at $50{ }^{\circ} \mathrm{C}$ for $180 \mathrm{~min}$. Subsequently, a temperature desorption was programmed at $5{ }^{\circ} \mathrm{C} / \mathrm{min}$. The $\mathrm{CO}_{2}$ signal was detected using a thermal conductivity detector (TCD).

(3) Scanning electron microscopy (SEM) and transmission electron microscopy (TEM). SEM images were obtained on a JEOL JSM-6700 scanning electron microscope at $6 \mathrm{kV}$ with the software package for automated electron tomography. Samples were prepared for TEM by dropping and drying ethanol dispersions of catalysts onto carbon-coated gold TEM grids at room temperature. TEM images were obtained by using a Titan G2 60-300 with an image corrector.

(4) X-ray photoelectron spectroscopy (XPS). For XPS, samples were thoroughly rinsed with deionized water and immersed into liquid nitrogen immediately after being removed from the electrochemical system. This effectively preserved the valence state and structure of the samples during the sample transfer. The samples were vacuum-dried and stored until the X-ray measurements were performed. XPS data were collected on an ESCALAB250Xi photoelectron spectrometer (Thermo Fisher Scientific) using a monochromatic Al Ka X-ray beam $(1,486.6 \mathrm{eV})$. All binding energies were referenced to the $\mathrm{C} 1 \mathrm{~s}$ peak $(284.6 \mathrm{eV})$.

(5) X-ray absorption spectroscopy (XAS) date collection and analysis. XAS spectra at the copper K edge were measured in fluorescence mode at the X-ray absorption station (beamline 1W2B) of the Beijing Synchrotron Radiation Facility (BSRF) in China using a double crystal Si (111) monochromator. The storage ring was working at the energy of $2.5 \mathrm{GeV}$ with an average electron current of $150 \mathrm{~mA}$. The incident and output beam intensities were monitored and recorded using ionization chambers filled with pure nitrogen.

An in situ home-made cell was employed for collecting in situ XAFS data. As-prepared $\mathrm{Cu}(\mathrm{OH})_{2} \mathrm{NWs}$, QMOF, and CMOF on Cu foil samples $(1 \times 5 \mathrm{~cm})$ were put into ethanol-filled hermetic containers $(8 \mathrm{~mL})$ 
separately and ultrasonic stripped for 30 min to obtain suspension containing superficial $\mathrm{Cu}(\mathrm{OH})_{2} \mathrm{NWs}$, QMOF, and CMOF powder, respectively. For each, $100 \mu \mathrm{L}$ of catalyst suspension and $25 \mu \mathrm{L}$ of $5 \%$ Nafion 117 solution were sonicated for $5 \mathrm{~min}$. Each catalyst ink was then uniformly loaded onto a fresh piece of thin carbon paper $(2 \mathrm{~cm} \times 5 \mathrm{~cm}$, thickness of $500 \mathrm{~nm})$ and allowed to dry in vacuum. The $\mathrm{Cu}(\mathrm{OH})_{2} \mathrm{NWs}$, QMOF, and CMOF powder on the thin carbon paper served as the working electrode, was in contact with a slip of copper tape, and was fixed with epoxy glue to the exterior of the wall of the cell, over the $0.8 \mathrm{~cm}$ hole, with the OFC or OBC layer facing inward. A Pt foil $(1 \mathrm{~cm} \times 1 \mathrm{~cm} \times 0.2 \mathrm{~cm})$ and a Ag/AgCl electrode ( $\mathrm{KCl}$ sat.) were used as the counter electrode and reference electrode, respectively.

The copper XAFS raw data processing was carried out by using ATHENA (Demeter 0.9.25, an interface to IFEFFIT) and ARTEMIS (Demeter 0.9.25) by the standard procedures. The $k 3$-weighted $\chi(k)$ data in the $k$ space ranging from 2.0 to $12 \AA^{-1}$ were Fourier-transformed to real (R) space using a Hann window ( $k$ k = $1.0 \AA^{-1}$ ) to separate the EXAFS contributions from different coordination shells. To obtain the detailed structural parameters around the $\mathrm{Cu}$ atom in the as-prepared samples, quantitative curve fittings were carried out for the Fourier-transformed $k 3 \chi(k)$ in R-space using the ARTEMIS module of IFEFFIT. During curve fittings, the Debye-Waller factor $\left(\sigma^{2}\right)$ and bond length $(R)$ were treated as adjustable parameters. No $\mathrm{R}$ factors yielded are larger than 0.01 , indicating the good fitting quality. The Morlet wavelet was chosen as the mother wavelet for the basic functions and the parameters $(\sigma=2, \eta=5)$ were used to achieve better resolution in the wave vector $k$.

(6) In situ IR Measurements. For in situ IR measurements, as-prepared QMOF sample was put into ethanol-filled hermetic containers $(8 \mathrm{~mL})$ separately and ultrasonic stripped for 30 min to obtain suspension containing superficial powder. $100 \mu \mathrm{L}$ of catalyst suspension and $25 \mu \mathrm{L}$ of $5 \%$ Nafion 117 solution were sonicated for $5 \mathrm{~min}$. Then $100 \mu \mathrm{L}$ of QMOF ink solution was casted onto the Au film coated Si prism. A homemade spectro-electrochemical cell (Figure S4) with three-electrode system was employed for collecting in situ IR data. The QMOF powder on the Si prism served as the working electrode. A coiled Pt wire served as counter electrode and a $\mathrm{Ag} / \mathrm{AgCl}$ electrode ( $\mathrm{KCl}$ sat.) served as reference electrode. In situ IR measurements were performed on a Thermo Scientific Nicolet iS50 FT-IR spectrometer with attenuated total reflection (ATR) configuration using a liquid nitrogen cooled MCT-A detector. All spectra were collected at a resolution of $4 \mathrm{~cm}^{-1}$ at a bottom-up incidence angle of ca. $67^{\circ}$. The FT-IR spectrometer was purified with high-purity argon for one hour. Before the test, the electrolyte was purified with high-purity $\mathrm{CO}_{2}$ for $30 \mathrm{~min}$. Time-resolved IR measurements at a fixed potential of $-0.4 \mathrm{~V}$ (vs RHE) were carried out with a time resolution of $\sim 2 \mathrm{~s}$. A CHI 660E electrochemistry workstation (CH Instruments, Inc.) was used for potential control.

Electrochemical measurements. Electrochemical measurements were performed at ambient temperature and pressure in a customized gastight $\mathrm{H}$-type glass cell separated by a Nafion 117 membrane (Fuel Cell Store). A CHI 660e potentiostat was employed to record the electrochemical response. A typical threeelectrode cell configuration was employed with a piece of platinum foil $(1 \mathrm{~cm} \times 1 \mathrm{~cm} \times 0.2 \mathrm{~cm})$ and a $\mathrm{Ag} / \mathrm{AgCl}$ electrode $(\mathrm{KCl}$ sat.) serving as the counter electrode and reference electrode, respectively. The 
area of the working electrode was fixed at $1 \mathrm{~cm}^{2}(0.5 \mathrm{~cm} \times 1 \mathrm{~cm} \times 2)$. All potentials measured were calibrated to the $\mathrm{RHE}$ scale as follows: $\mathrm{VRHE}=\mathrm{V}_{\mathrm{Ag} / \mathrm{AgCl}}(\mathrm{KCl}$ sat. $)+0.197 \mathrm{~V}+0.059 \mathrm{~V} \times \mathrm{pH}$. Ultrahigh purity $\mathrm{CO}_{2}(99.99 \%)$ was purged into the $0.1 \mathrm{M} \mathrm{KHCO}_{3}$ solution for at least 30 minutes to make a $\mathrm{CO}_{2}{ }^{-}$ saturated $0.1 \mathrm{M} \mathrm{KHCO}_{3}$ aqueous solution ( $\mathrm{pH}=6.8$ ). In a typical experiment, $145 \mathrm{~mL}$ of $\mathrm{CO}_{2}$-saturated 0.1 $\mathrm{M} \mathrm{KHCO}_{3}$ aqueous solution was magnetically stirred in the cathodic compartment with a headspace of $50 \mathrm{~mL}$. The electrode was held at a constant bias using chronoamperometry for $5 \mathrm{C}$ of charge, after which a $500 \mu \mathrm{L}$ gas sample was taken by a syringe (Hamilton) from the headspace. The gas was injected into a gas chromatograph instrument (GC-2014, Serial No. C11484403556 SA, Shimadzu, Japan) equipped with a flame ionization detector (FID) for detection of organic compounds and a gas chromatograph instrument (Serial No. C11485013433 SA, Shimadzu, Japan) equipped with a thermal conductivity detector (TCD) for detection of inorganic gases. Ultrahigh purity $\mathrm{N}_{2}(99.99 \%)$ was used as the carrier gas. The concentration of product gases was determined using calibration curves from standard gases (Newradar special gas). Liner sweep voltammetry (LSV) was conducted with a scan rate of $5 \mathrm{mV} / \mathrm{s}$. For comparison, LSV measurements were performed in an $\operatorname{Ar}(99.99 \%)$-saturated $0.1 \mathrm{M} \mathrm{KHCO}_{3}$ aqueous solution. All current densities were normalized to the geometrical area of the electrode.

The Faradaic efficiency can be calculated as follows: see formula 1 in the supplementary files.

where $n_{i}$ is the number of electrons required to produce an i molecule, which is $2,2,8$, and 12 for $\mathrm{CO}, \mathrm{H}_{2}$, $\mathrm{CH}_{4}$, and $\mathrm{C}_{2} \mathrm{H}_{4}$, respectively; $F$ is the Faradaic constant $\left(96,485.33289 \mathrm{C} \mathrm{mol}^{-1}\right) ; P_{0}$ is the atmospheric pressure $(1.013 \times 105 \mathrm{~Pa}) ; T_{0}$ is the reaction temperature $(298 \mathrm{~K}) ; \mathrm{R}$ is the ideal gas constant $(8.314 \mathrm{~J}$ $\left.\mathrm{mol}^{-1} \mathrm{~K}^{-1}\right) ; V_{o}$ is the total headspace volume (typically $50 \mathrm{~mL}$ ); $V_{i}(\mathrm{vol} \%)$ is the measured volume concentration of product $i$ from the electrochemical cell at a given passing charge (typically 5 coulombs); $Q_{\text {total }}$ is the total amount of charge $Q$ (in units of coulombs) passed through the sample ( 5 coulombs); and $Q_{i}$ is the amount of charge $Q$ to produce species $i$ from $\mathrm{CO}_{2}$.

DFT calculations. By using the Cambridge Serial Total Energy Package (CASTEP) in Materials Studio, all density functional theory (DFT) calculations were performed with the plane-wave pseudopotential method to apply first-principles-based quantum mechanics simulations. In this work, the spin generalized gradient approximation (SGGA) within Perdew-Burke-Ernzerhof (PBE) form was setup as an exchangecorrelation function. A $3 \times 3 \times 1$ Monkhorst-Pack k-points grid was used for k-points sampling, and $900 \mathrm{eV}$ plane-wave expansion was setup for energy cut-offs. These parameters were carefully tested. The $\mathrm{Cu}-$ $3 d^{10} 4 s^{1}, 0-2 s^{2} 2 p^{4}, C-2 s^{2} 2 p^{2}$, and $H-1 s^{1}$ were setup for valence states. A vacuum slab of about $15 \AA$ was maintained in the super-cell configuration that was large enough for the calculations. The SCF tolerance for geometrical optimization and phonon calculations was less than $1 \mathrm{e}^{-6} \mathrm{eV} \cdot \mathrm{atom}^{-1}$.

\section{References}

1. Diercks CS, Liu Y, Cordova KE, Yaghi OM. The role of reticular chemistry in the design of CO2 reduction catalysts. Nat. Mater. 2018, 17(4): 301-307. 
2. Furukawa H, Cordova KE, O'Keeffe M, Yaghi OM. The Chemistry and Applications of Metal-Organic Frameworks. Science 2013, 341(6149): 974-+.

3. Wang Q, Astruc D. State of the Art and Prospects in Metal-Organic Framework (MOF)-Based and MOF-Derived Nanocatalysis. Chem. Rev. 2020, 120(2): 1438-1511.

4. Yaghi OM, O'Keeffe M, Ockwig NW, Chae HK, Eddaoudi M, Kim J. Reticular synthesis and the design of new materials. Nature 2003, 423(6941): 705-714.

5. Chui SSY, Lo SMF, Charmant JPH, Orpen AG, Williams ID. A Chemically Functionalizable Nanoporous Material $\left[\mathrm{Cu}_{3}(\mathrm{TMA})_{2}\left(\mathrm{H}_{2} \mathrm{O}\right)_{3}\right]_{n}$. Science 1999, 283(5405): 1148 .

6. Hori Y. Electrochemical $\mathrm{CO}_{2}$ Reduction on Metal Electrodes. In: Vayenas $\mathrm{CG}$, White RE, GamboaAldeco ME (eds). Modern Aspects of Electrochemistry. Springer New York: New York, NY, 2008, pp 89189.

7. Deng X, Li R, Wu S, Wang L, Hu J, Ma J, et al. Metal-Organic Framework Coating Enhances the Performance of $\mathrm{Cu}_{2} \mathrm{O}$ in Photoelectrochemical $\mathrm{CO}_{2}$ Reduction. J. Am. Chem. Soc. 2019, 141(27): 10924-10929.

8. Nam DH, Bushuyev OS, Li J, De Luna P, Seifitokaldani A, Dinh CT, et al. Metal-Organic Frameworks Mediate $\mathrm{Cu}$ Coordination for Selective $\mathrm{CO}_{2}$ Electroreduction. J. Am. Chem. Soc. 2018, 140(36): 11378-11386.

9. Yao K, Xia Y, Li J, Wang N, Han J, Gao C, et al. Metal-organic framework derived copper catalysts for $\mathrm{CO}_{2}$ to ethylene conversion. J. Mater. Chem. A 2020, 8(22): 11117-11123.

10. Weng Z, Wu Y, Wang M, Jiang J, Yang K, Huo S, et al. Active sites of copper-complex catalytic materials for electrochemical carbon dioxide reduction. Nat. Commun. 2018, 9(1): 415.

11. Zhu Q, Sun X, Yang D, Ma J, Kang X, Zheng L, et al. Carbon dioxide electroreduction to C2 products over copper-cuprous oxide derived from electrosynthesized copper complex. Nat. Commun. 2019, 10(1): 3851.

12. Albo J, Vallejo D, Beobide G, Castillo O, Castaño P, Irabien A. Copper-Based Metal-Organic Porous Materials for $\mathrm{CO}_{2}$ Electrocatalytic Reduction to Alcohols. ChemSusChem 2017, 10(6): 1100-1109.

13. Nitopi S, Bertheussen E, Scott SB, Liu X, Engstfeld AK, Horch S, et al. Progress and Perspectives of Electrochemical CO2 Reduction on Copper in Aqueous Electrolyte. Chem. Rev. 2019, 119: 7610-7672.

14. Zheng Y, Vasileff A, Zhou X, Jiao Y, Jaroniec M, Qiao SZ. Understanding the Roadmap for Electrochemical Reduction of $\mathrm{CO}_{2}$ to Multi-Carbon Oxygenates and Hydrocarbons on Copper-Based Catalysts. J. Am. Chem. Soc. 2019, 141(19): 7646-7659.

15. Jiang K, Sandberg RB, Akey AJ, Liu X, Bell DC, Nørskov JK, et al. Metal ion cycling of Cu foil for selective $\mathrm{C}-\mathrm{C}$ coupling in electrochemical $\mathrm{CO}_{2}$ reduction. Nat. Catal. 2018, 1(2): 111-119.

16. Dissegna S, Epp K, Heinz WR, Kieslich G, Fischer RA. Defective Metal-Organic Frameworks. Adv. Mater. 2018, 30(37): e1704501.

17. Fang Z, Bueken B, De Vos DE, Fischer RA. Defect-Engineered Metal-Organic Frameworks. Angew. Chem. Int. Ed. Engl. 2015, 54(25): 7234-7254. 
18. Tsumori N, Chen L, Wang Q, Zhu Q-L, Kitta M, Xu Q. Quasi-MOF: Exposing Inorganic Nodes to Guest Metal Nanoparticles for Drastically Enhanced Catalytic Activity. Chem 2018, 4(4): 845-856.

19. Fang Z, Durholt JP, Kauer M, Zhang W, Lochenie C, Jee B, et al. Structural complexity in metal-organic frameworks: simultaneous modification of open metal sites and hierarchical porosity by systematic doping with defective linkers. J. Am. Chem. Soc. 2014, 136(27): 9627-9636.

20. Zhang H-Y, Shi R-H, Fan H-L, Yang C, Zhang C-N, Wang Y-S, et al. Defect creation by benzoic acid in Cu-Based Metal-Organic frameworks for enhancing sulfur capture. Microporous Mesoporous Mater. 2020, 298: 110070.

21. Tao L, Lin C-Y, Dou S, Feng S, Chen D, Liu D, et al. Creating coordinatively unsaturated metal sites in metal-organic-frameworks as efficient electrocatalysts for the oxygen evolution reaction: Insights into the active centers. Nano Energy 2017, 41: 417-425.

22. Kang X, Lyu K, Li L, Li J, Kimberley L, Wang B, et al. Integration of mesopores and crystal defects in metal-organic frameworks via templated electrosynthesis. Nat. Commun. 2019, 10(1): 4466.

23. Xue Z, Liu K, Liu Q, Li Y, Li M, Su CY, et al. Missing-linker metal-organic frameworks for oxygen evolution reaction. Nat. Commun. 2019, 10(1): 5048.

24. Handoko AD, Wei F, Jenndy, Yeo BS, Seh ZW. Understanding heterogeneous electrocatalytic carbon dioxide reduction through operando techniques. Nat. Catal. 2018, 1(12): 922-934.

25. Zhang W, Huang C, Xiao Q, Yu L, Shuai L, An P, et al. Atypical Oxygen-Bearing Copper Boosts Ethylene Selectivity toward Electrocatalytic $\mathrm{CO}_{2}$ Reduction. J. Am. Chem. Soc. 2020, 142(26): 1141711427.

26. Grosse P, Gao D, Scholten F, Sinev I, Mistry H, Roldan Cuenya B. Dynamic Changes in the Structure, Chemical State and Catalytic Selectivity of Cu Nanocubes during $\mathrm{CO}_{2}$ Electroreduction: Size and Support Effects. Angew. Chem. Int. Ed. Engl. 2018, 57(21): 6192-6197.

27. Jeon HS, Sinev I, Scholten F, Divins NJ, Zegkinoglou I, Pielsticker L, et al. Operando Evolution of the Structure and Oxidation State of Size-Controlled Zn Nanoparticles during $\mathrm{CO}_{2}$ Electroreduction. J. Am. Chem. Soc. 2018, 140(30): 9383-9386.

28. Birdja YY, Pérez-Gallent E, Figueiredo MC, Göttle AJ, Calle-Vallejo F, Koper MTM. Advances and challenges in understanding the electrocatalytic conversion of carbon dioxide to fuels. Nat. Energy 2019, 4(9): 732-745.

29. Zugic B, Wang L, Heine C, Zakharov DN, Lechner BAJ, Stach EA, et al. Dynamic restructuring drives catalytic activity on nanoporous gold-silver alloy catalysts. Nat. Mater. 2017, 16(5): 558-564.

30. Arán-Ais RM, Scholten F, Kunze S, Rizo R, Roldan Cuenya B. The role of in situ generated morphological motifs and $\mathrm{Cu}(\mathrm{i})$ species in $\mathrm{C}_{2+}$ product selectivity during $\mathrm{CO}_{2}$ pulsed electroreduction. Nat. Energy 2020, 5(4): 317-325.

31. Liu L, Chen Z, Wang J, Zhang D, Zhu Y, Ling S, et al. Imaging defects and their evolution in a metalorganic framework at sub-unit-cell resolution. Nat Chem 2019, 11(7): 622-628. 
32. Zhang W, Wen X, Yang S, Berta Y, Wang ZL. Single-Crystalline Scroll-Type Nanotube Arrays of Copper Hydroxide Synthesized at Room Temperature. Adv. Mater. 2003, 15(10): 822-825.

33. Prestipino C, Regli L, Vitillo JG, Bonino F, Damin A, Lamberti C, et al. Local Structure of Framework $\mathrm{Cu}(\mathrm{II})$ in HKUST-1 Metallorganic Framework: Spectroscopic Characterization upon Activation and Interaction with Adsorbates. Chem. Mater. 2006, 18(5): 1337-1346.

34. Dhumal NR, Singh MP, Anderson JA, Kiefer J, Kim HJ. Molecular Interactions of a Cu-Based MetalOrganic Framework with a Confined Imidazolium-Based Ionic Liquid: A Combined Density Functional Theory and Experimental Vibrational Spectroscopy Study. J. Phys. Chem. C 2016, 120(6): 3295-3304.

35. Todaro M, Alessi A, Sciortino L, Agnello S, Cannas M, Gelardi FM, et al. Investigation by Raman Spectroscopy of the Decomposition Process of HKUST-1 upon Exposure to Air. J. Spectrosc. 2016, 2016: 1-7.

36. Jabbari V, Veleta JM, Zarei-Chaleshtori M, Gardea-Torresdey J, Villagrán D. Green synthesis of magneticMOF@GO and MOF@CNT hybrid nanocomposites with high adsorption capacity towards organic pollutants. Chem. Eng. J. 2016, 304: 774-783.

37. Raoof J-B, Hosseini SR, Ojani R, Mandegarzad S. MOF-derived Cu/nanoporous carbon composite and its application for electro-catalysis of hydrogen evolution reaction. Energy 2015, 90: 1075-1081.

38. Decoste JB, Peterson GW, Smith MW, Stone CA, Willis CR. Enhanced stability of Cu-BTC MOF via perfluorohexane plasma-enhanced chemical vapor deposition. J. Am. Chem. Soc. 2012, 134(3): 1486-1489.

39. Nan J, Dong X, Wang W, Jin W, Xu N. Step-by-Step Seeding Procedure for Preparing HKUST-1 Membrane on Porous a-Alumina Support. Langmuir 2011, 27(8): 4309-4312.

40. Kozachuk O, Yusenko K, Noei H, Wang Y, Walleck S, Glaser T, et al. Solvothermal growth of a ruthenium metal-organic framework featuring HKUST-1 structure type as thin films on oxide surfaces. Chem. Commun. 2011, 47(30): 8509-8511.

41. Ania CO, Seredych M, Rodriguez-Castellon E, Bandosz TJ. New copper/GO based material as an efficient oxygen reduction catalyst in an alkaline medium: The role of unique $\mathrm{Cu} / \mathrm{rGO}$ architecture. Appl. Catal. B-Environ. 2015, 163: 424-435.

42. Luo Y, Estudillo-Wong LA, Cavillo L, Granozzi G, Alonso-Vante N. An easy and cheap chemical route using a MOF precursor to prepare $\mathrm{Pd}-\mathrm{Cu}$ electrocatalyst for efficient energy conversion cathodes. $J$. Catal. 2016, 338: 135-142.

43. Travlou NA, Singh K, Rodríguez-Castellón E, Bandosz TJ. Cu-BTC MOF-graphene-based hybrid materials as low concentration ammonia sensors. J. Mater. Chem. A 2015, 3(21): 11417-11429.

44. Deng $X$, Verdaguer A, Herranz T, Weis C, Bluhm H, Salmeron M. Surface Chemistry of $\mathrm{Cu}$ in the Presence of $\mathrm{CO}_{2}$ and $\mathrm{H}_{2} \mathrm{O}$. Langmuir 2008, 24(17): 9474-9478.

45. Dinh C-T, Jain A, de Arquer FPG, De Luna P, Li J, Wang N, et al. Multi-site electrocatalysts for hydrogen evolution in neutral media by destabilization of water molecules. Nat. Energy 2018, 4(2): 107-114. 
46. Duke AS, Dolgopolova EA, Galhenage RP, Ammal SC, Heyden A, Smith MD, et al. Active Sites in Copper-Based Metal-Organic Frameworks: Understanding Substrate Dynamics, Redox Processes, and Valence-Band Structure. J. Phys. Chem. C2015, 119(49): 27457-27466.

47. Huang C, Dong J, Sun W, Xue Z, Ma J, Zheng L, et al. Coordination mode engineering in stackednanosheet metal-organic frameworks to enhance catalytic reactivity and structural robustness. Nat. Commun. 2019, 10(1): 2779.

48. Peter Kappen J-DG, Birgitte S. Hammershøi, Larc Tr “oger, Bjerne S. Clausen. The State of Cu Promoter Atoms in High-Temperature Shift Catalysts-An in Situ Fluorescence XAFS Study. J. Catal. 2001, 198: 56-65.

49. Floriano PN, Noble, Schoonmaker JM, Poliakoff ED, McCarley RL. Cu(0) Nanoclusters Derived from Poly(propylene imine) Dendrimer Complexes of Cu(II). J. Am. Chem. Soc. 2001, 123(43): 1054510553.

50. Sun W, Song Y, Gong XQ, Cao LM, Yang J. An efficiently tuned d-orbital occupation of IrO 2 by doping with $\mathrm{Cu}$ for enhancing the oxygen evolution reaction activity. Chem. Sci. 2015, 6(8): 4993-4999.

51. Ikuno T, Zheng J, Vjunov A, Sanchez-Sanchez M, Ortuno MA, Pahls DR, et al. Methane Oxidation to Methanol Catalyzed by Cu-OxO Clusters Stabilized in NU-1000 Metal-Organic Framework. J. Am. Chem. Soc. 2017, 139(30): 10294-10301.

52. Sun X-P, Sun F-F, Gu S-Q, Chen J, Du X-L, Wang J-Q, et al. Local structural evolutions of $\mathrm{CuO} / \mathrm{ZnO} / \mathrm{Al}_{2} \mathrm{O}_{3}$ catalyst for methanol synthesis under operando conditions studied by in situ quick X-ray absorption spectroscopy. Nucl. Sci. Tech. 2016, 28(2).

53. Peng J, Chen B, Wang Z, Guo J, Wu B, Hao S, et al. Surface coordination layer passivates oxidation of copper. Nature 2020, 586(7829): 390-394.

54. Zhang B, Zhang J, Shi J, Tan D, Liu L, Zhang F, et al. Manganese acting as a high-performance heterogeneous electrocatalyst in carbon dioxide reduction. Nat. Commun. 2019, 10(1): 2980.

55. Yang HB, Hung S-F, Liu S, Yuan K, Miao S, Zhang L, et al. Atomically dispersed Ni(1) as the active site for electrochemical $\mathrm{CO}_{2}$ reduction. Nat. Energy 2018, 3(2): 140-147.

56. Norskov JK, Abild-Pedersen F, Studt F, Bligaard T. Density functional theory in surface chemistry and catalysis. Proc. Natl Acad. Sci. USA 2011, 108(3): 937-943.

\section{Declarations}

\section{Acknowledgements}

This work was financially supported by National Natural Science Foundation of China (Nos. 51872108 and U20A20246), the Fundamental Research Funds for the Central Universities (No. CCNU20TS006) and the China Postdoctoral Science Foundation (No. 20201jb015). Prof. J. Zhang would like to thank National Key Research and Development Program of China (No. 2017YFA0403400).

\section{Author contributions}


Y.Y., L.M. and Z.Y. supervised the project. W.Z. designed and synthesized the nanomaterials and performed most of the experiments. W.Z., C.H. and R.Y. performed electron microscopy tests. W.Z. and J.Z. performed FT-IR and Raman tests. W.Z., J.Z. and P.A. performed the XAFS measurements. Y.W, Q.Z. and M.Q. conducted and discussed the theoretical calculations. W.Z. wrote the initial draft of the manuscript. All authors discussed the results and edited the manuscript.

\section{Competing interests}

The authors declare no competing interests.

\section{Figures}

a

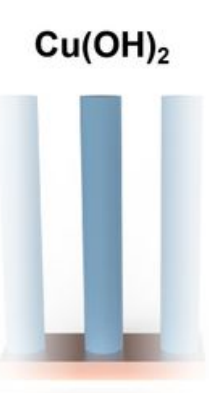

b

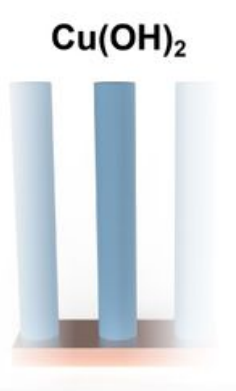

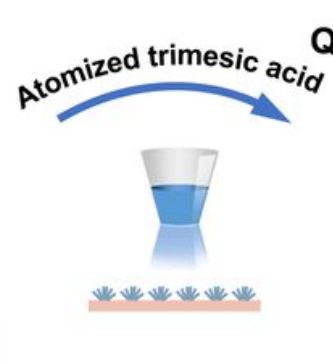

Quasi-MOF (QMOF)

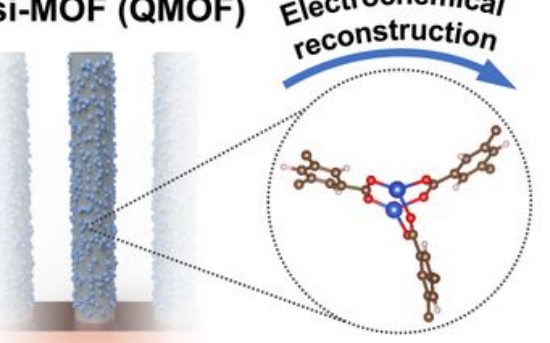

Complete-MOF (CMOF)

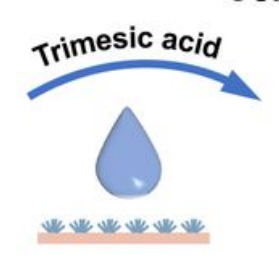

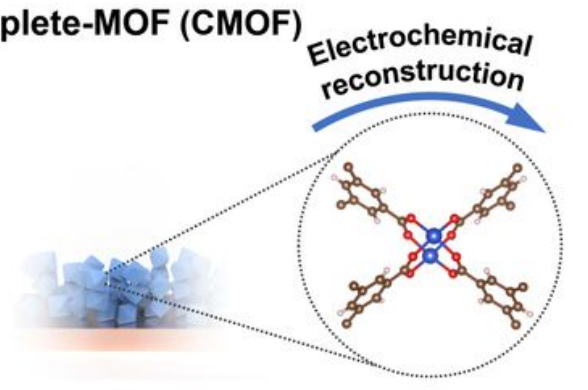

CU-CPWC

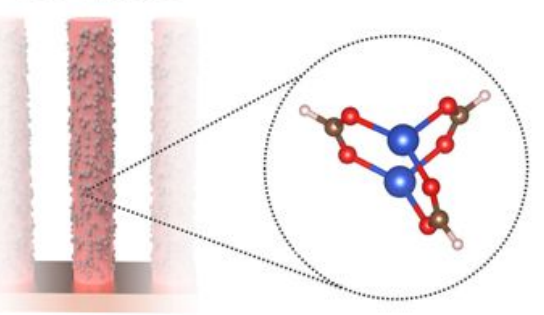

CPW

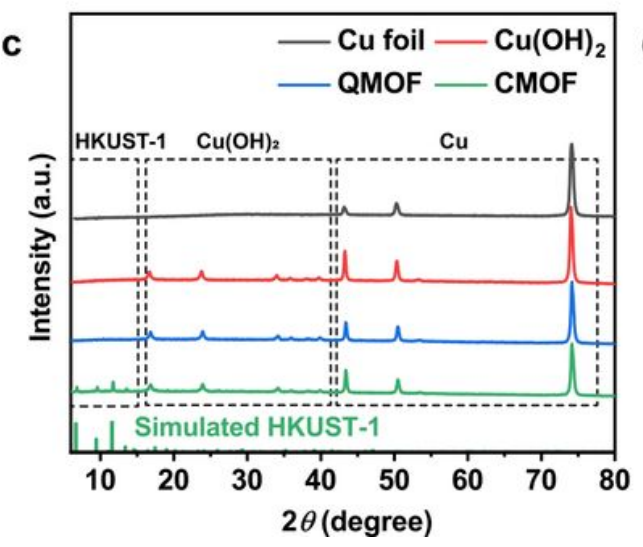

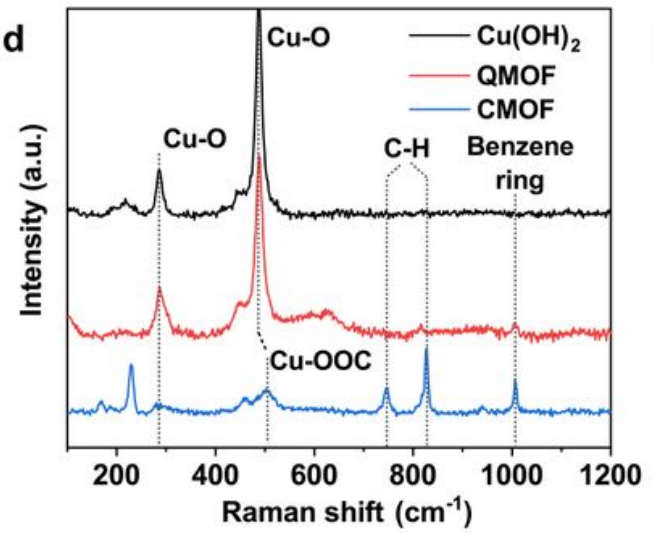

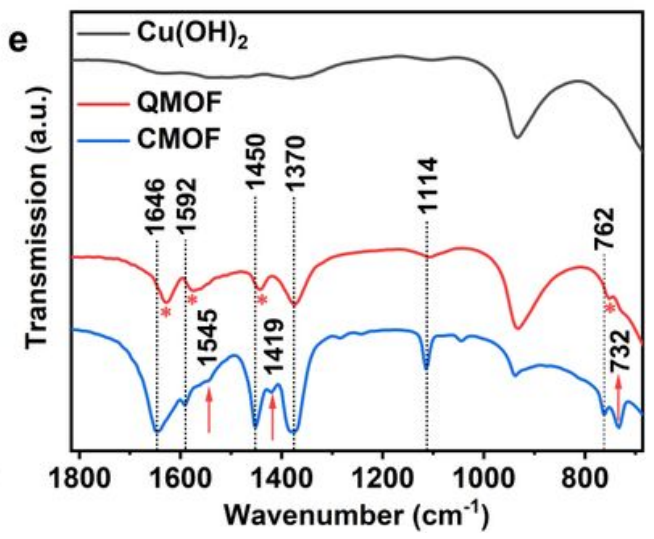

Figure 1

Electrocatalyst design and structural characterizations. a, b Schematic illustration of the synthetic procedures for $\mathrm{CU}-\mathrm{CPWC}$ and CPW electrocatalyst. c XRD patterns of pristine $\mathrm{Cu}$ foil, $\mathrm{Cu}(\mathrm{OH}) 2, \mathrm{QMOF}$ and 
CMOF. d Raman spectra of pristine $\mathrm{Cu}(\mathrm{OH}) 2$, QMOF and CMOF. e FTIR spectra of pristine $\mathrm{Cu}(\mathrm{OH}) 2$, QMOF and CMOF.
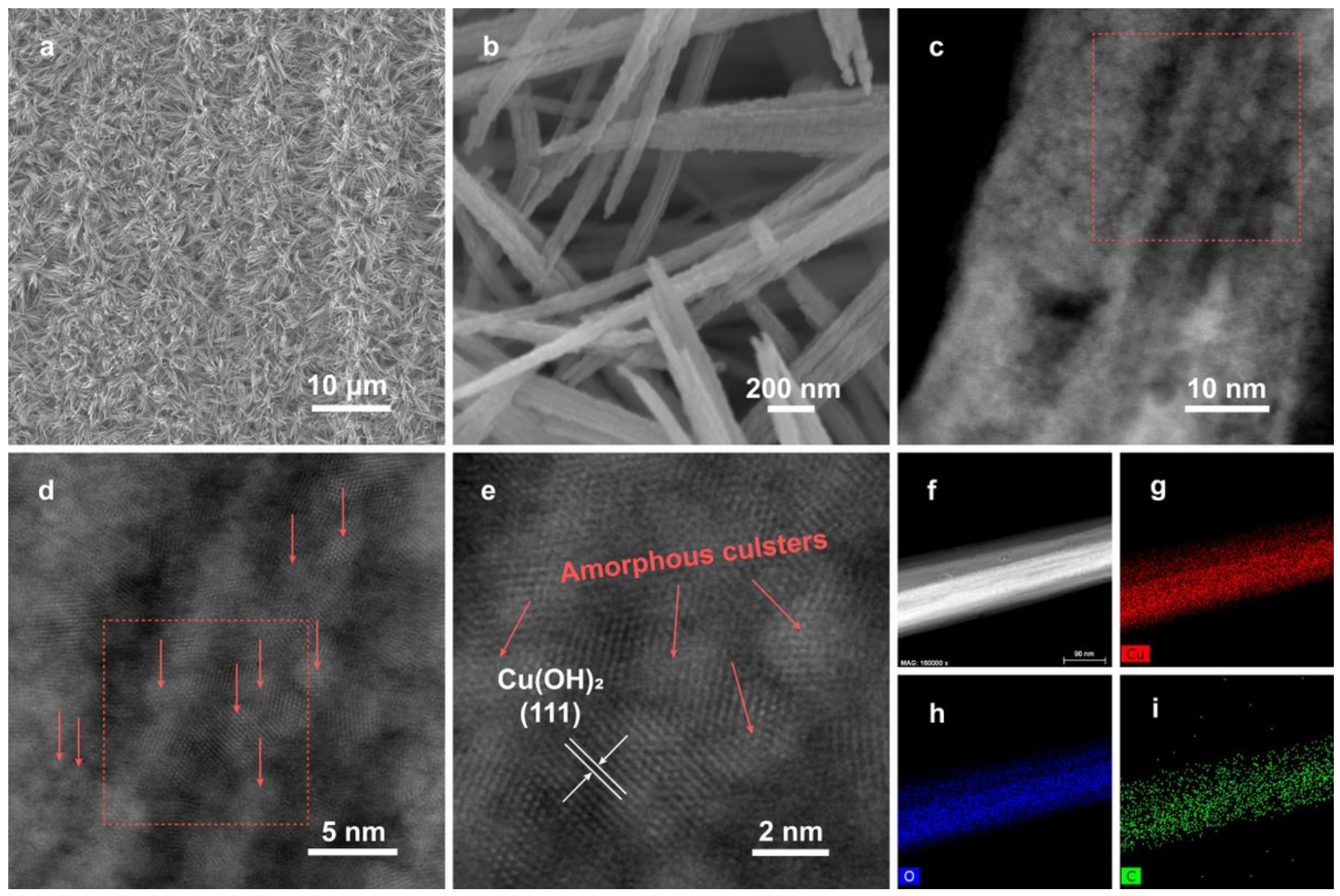

\section{Figure 2}

SEM and TEM characterizations of QMOF. a,b SEM images of QMOF. c-e HRTEM images of QMOF. $f$, HAADF-TEM image of QMOF. g-i The corresponding elemental mapping. 
a

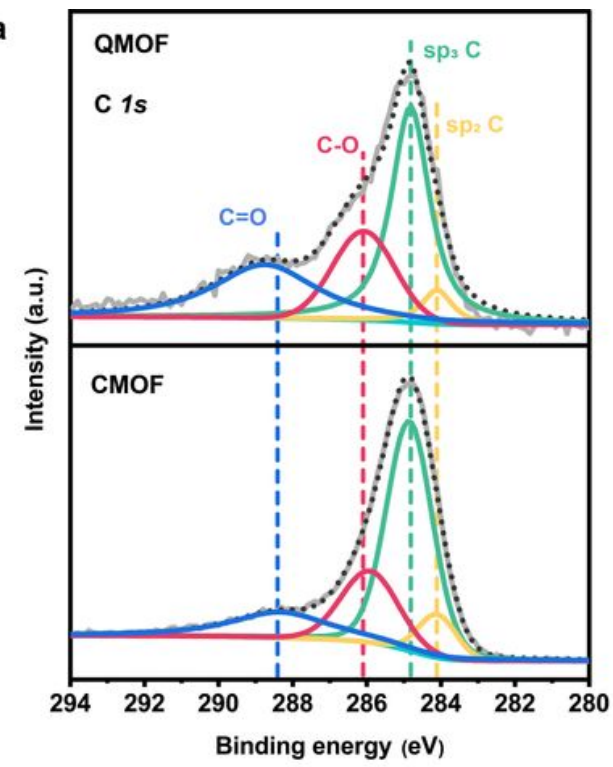

d

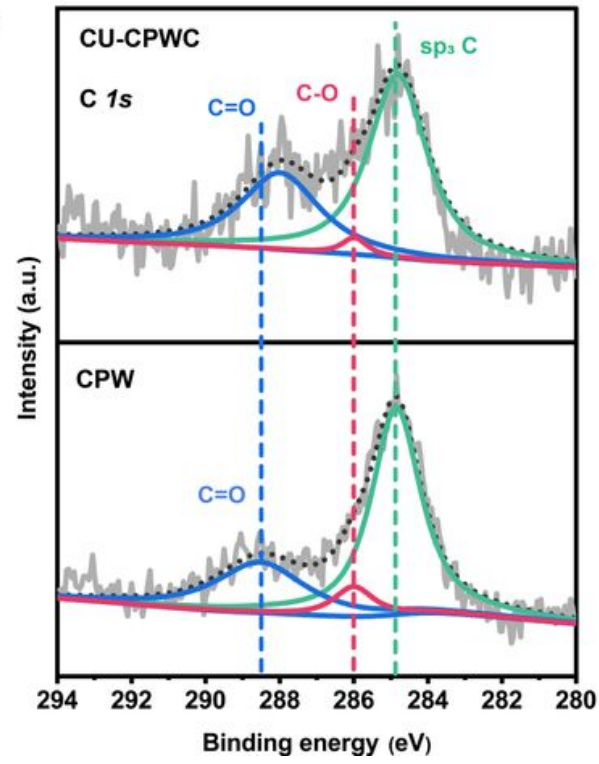

b

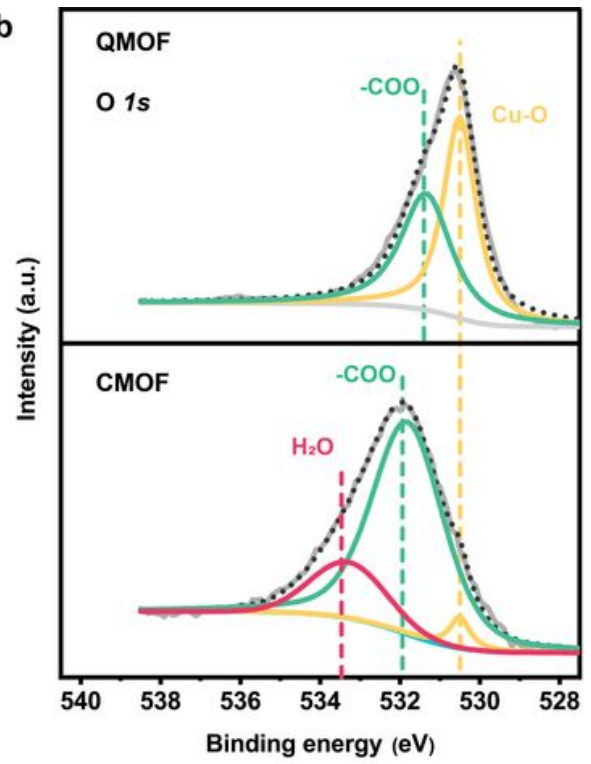

e

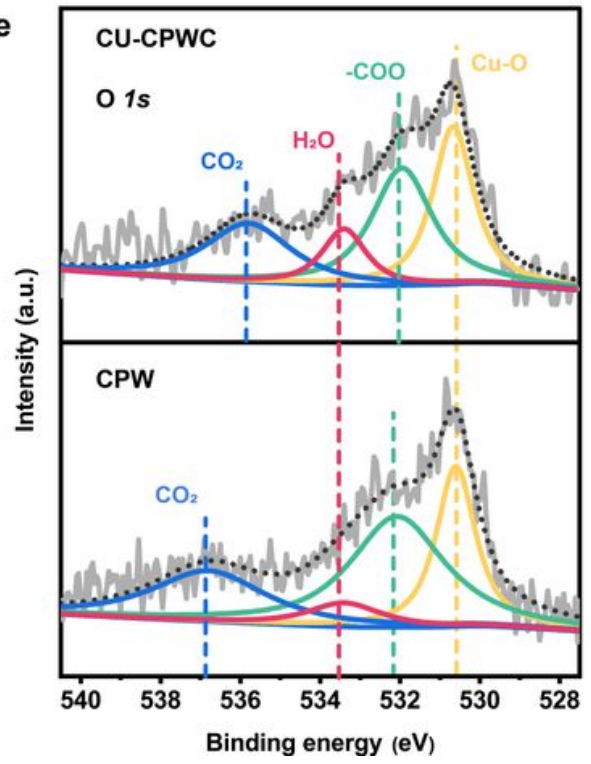

c

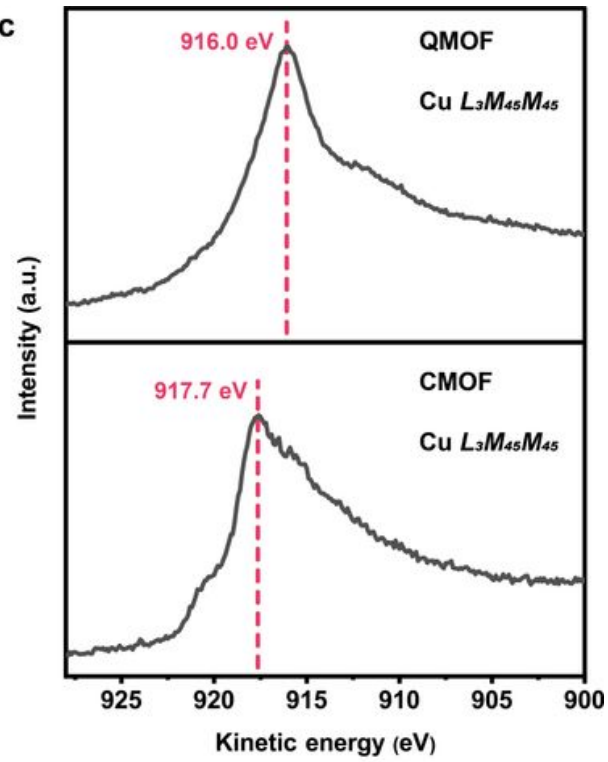

f

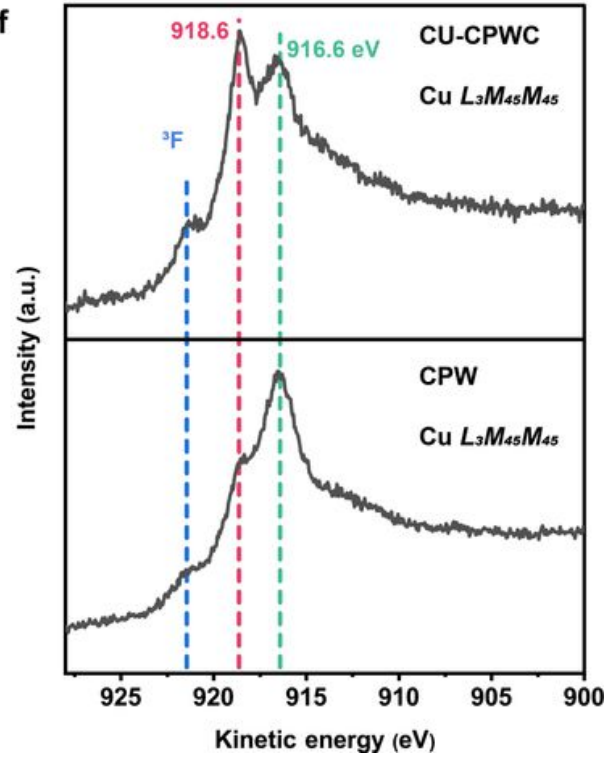

Figure 3

Structural characterizations of samples by XPS spectroscopy. a-c Ex-situ XPS spectra of pristine QMOF and CMOF samples in C 1s, 0 1s and Cu Auger region. d-f Quasi-in situ XPS spectra of CU-CPWC and CPW samples in $\mathrm{C} 1 \mathrm{~s}, \mathrm{O} 1 \mathrm{~s}$ and $\mathrm{Cu}$ Auger region. 
a

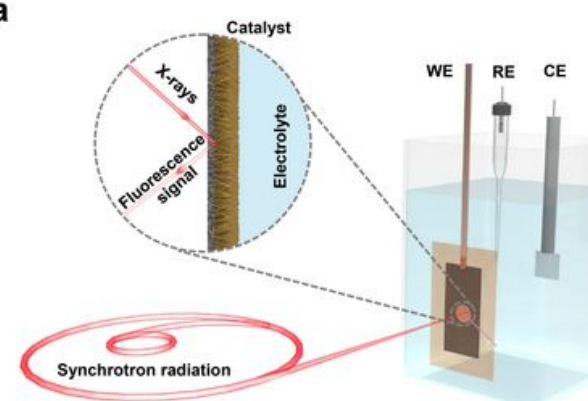

d

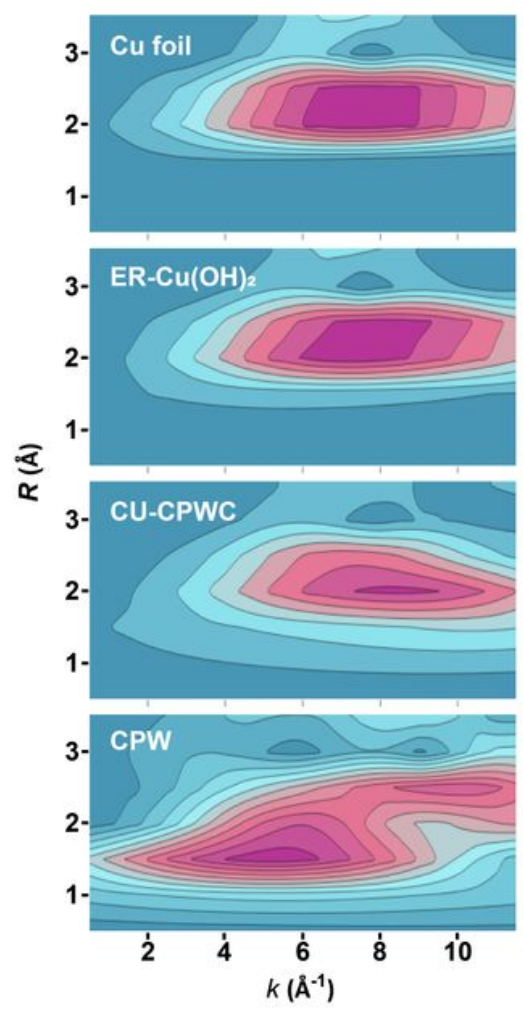

b

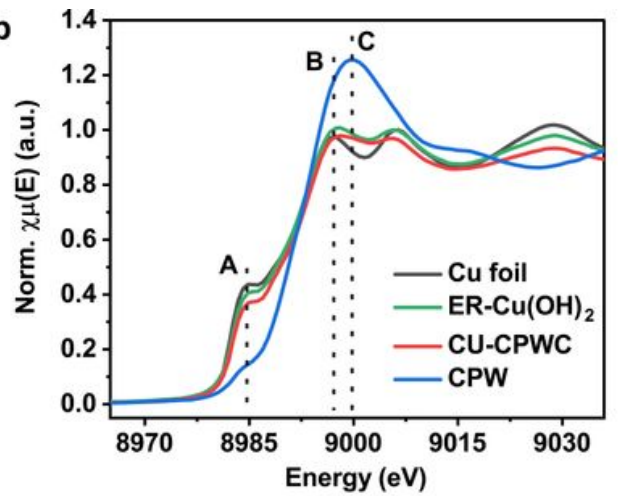

e

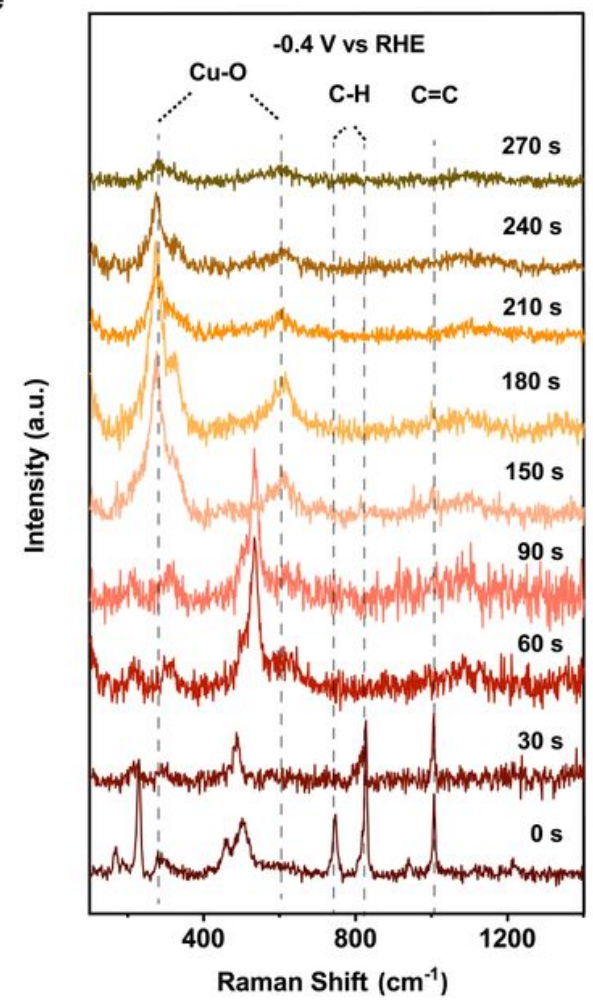

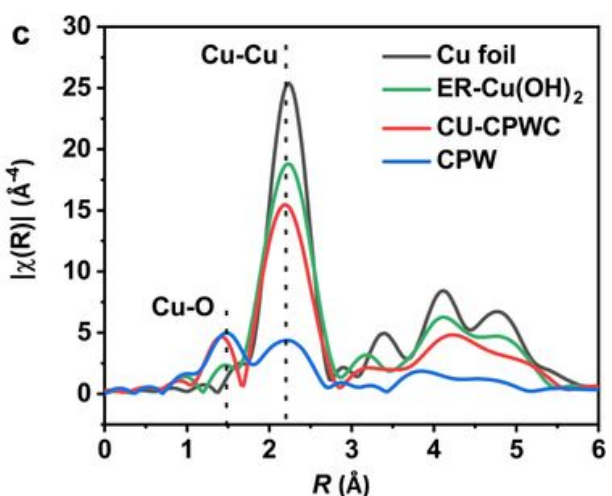

f 1
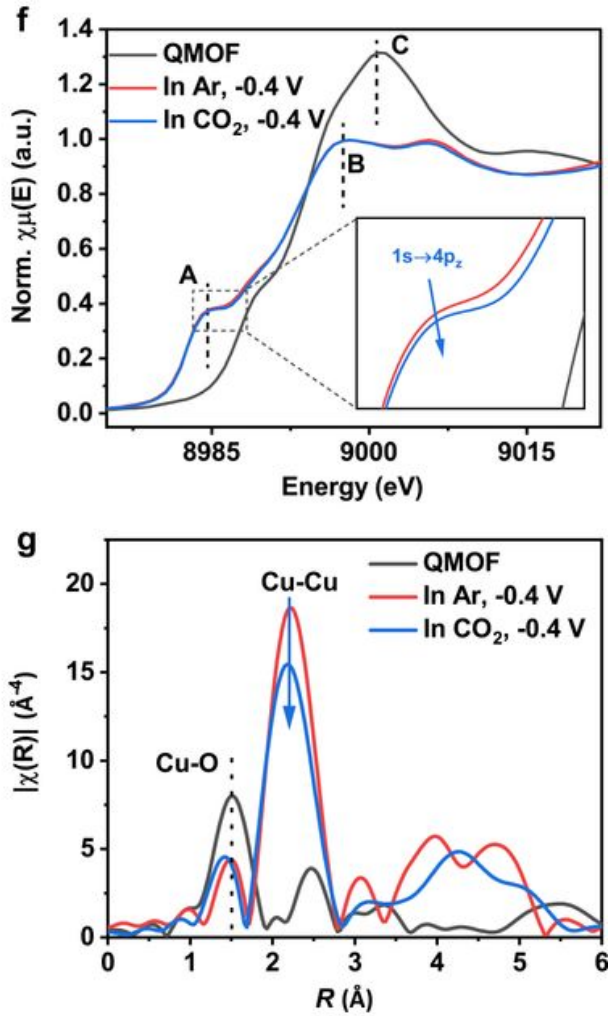

Figure 4

Structural characterizations of samples by in situ XAS and in situ Raman. a Schematic illustration of the in situ XAS experiment. b Normalized Cu K-edge XANES spectra of four samples under - $0.4 \mathrm{~V}$ in $\mathrm{CO} 2-$ saturated $0.1 \mathrm{M} \mathrm{KHCO} 3$ aqueous solution. c Corresponding k3-weighted FT-EXAFS spectra. d Morlet WT of the k3-weighted EXAFS data for the four samples with parameters of $\sigma=2$ and $\eta=5$. e In situ Raman spectra of CMOF under -0.4 V in CO2-saturated 0.1 M KHCO3 aqueous solution. f Normalized Cu K-edge XANES spectra of QMOF under -0.4 V in CO2-saturated and Ar-saturated $0.1 \mathrm{M} \mathrm{KHCO3}$ aqueous solution. g Corresponding k3-weighted FT-EXAFS spectra. 

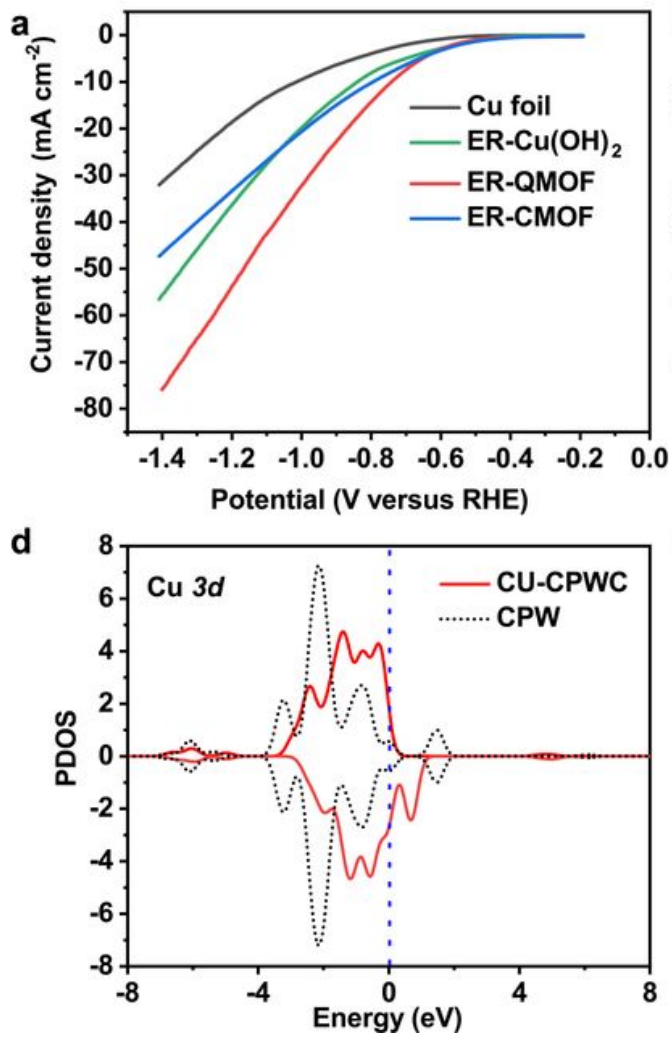
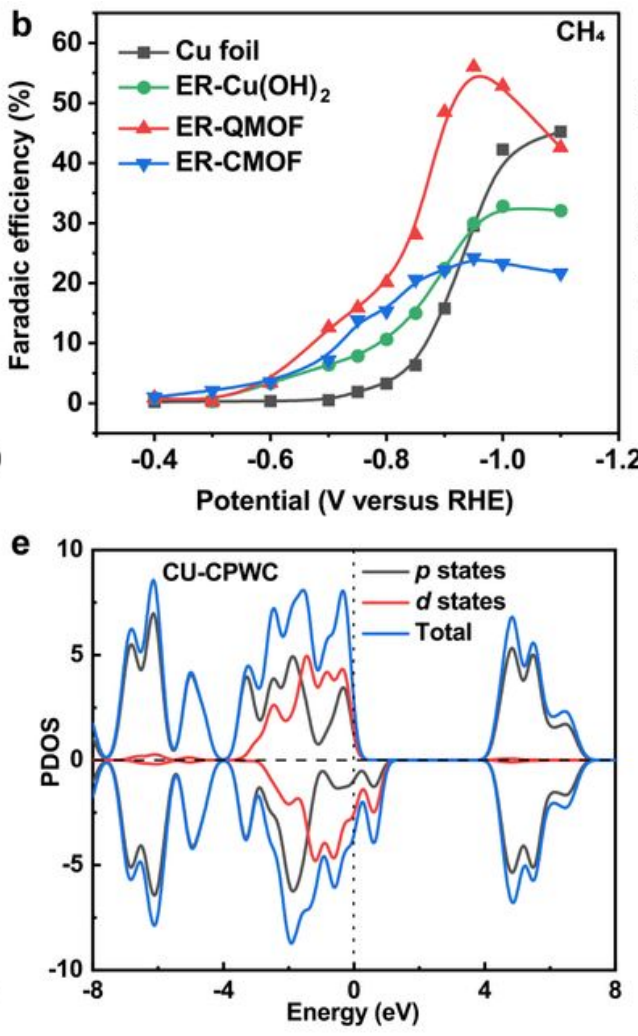
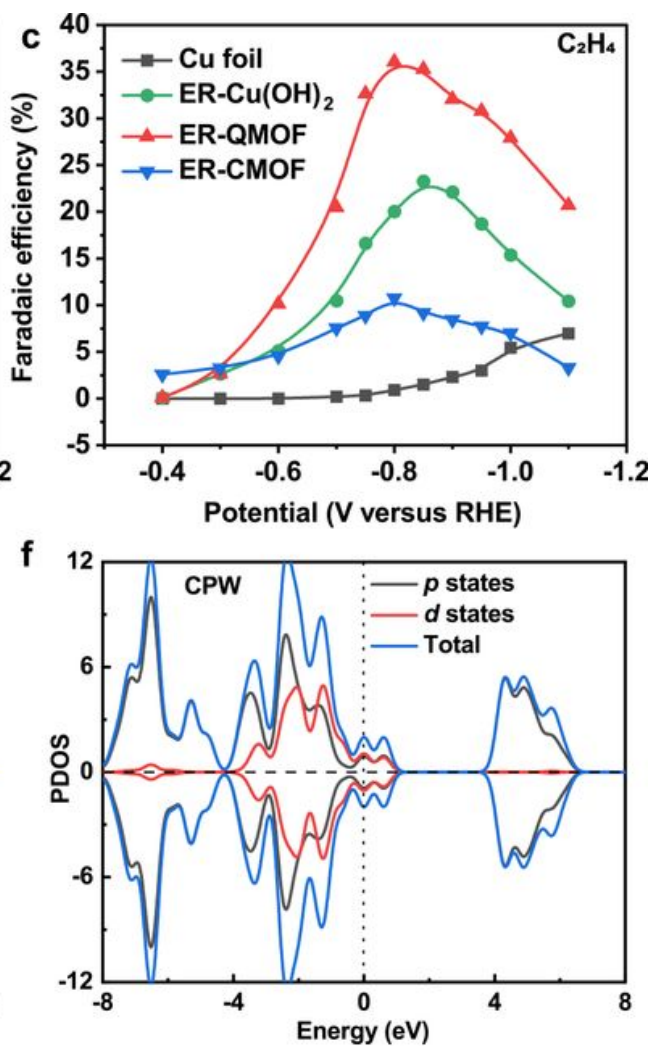

Figure 5

Evaluation of catalytic activity by electrochemical measurements and DFT simulations. a LSV curves of $\mathrm{Cu}$ foil, ER-Cu(OH)2, CU-CPWC and CPW. b,c Faradaic efficiencies for $\mathrm{CH} 4$ and $\mathrm{C} 2 \mathrm{H} 4$ respectively at selected potentials on the four samples. $d$ Spin-orbit projected 3d density of states of CU-CPWC and CPW. e Spin-orbit projected density of states of CU-CPWC with CO2 adsorption. $f$ Spin-orbit projected density of states of CPW with $\mathrm{CO} 2$ adsorption.

\section{Supplementary Files}

This is a list of supplementary files associated with this preprint. Click to download.

- Supplementarylnformation.docx

- SupplementaryInformation.docx 